\title{
Sorafenib inhibits vascular endothelial cell proliferation stimulated by anaplastic thyroid cancer cells regardless of $B R A F$ mutation status
}

\author{
SAE ISHIHARA*, NAOYOSHI ONODA*, SATORU NODA, YUKA ASANO, YUKIE TAUCHI, \\ TAMAMI MORISAKI, SHINICHIRO KASHIWAGI, TSUTOMU TAKASHIMA and MASAICHI OHIRA
}

Department of Breast and Endocrine Surgery, Osaka City University Graduate School of Medicine, Osaka 545-8585, Japan

Received May 7, 2019; Accepted September 6, 2019

DOI: $10.3892 /$ ijo.2019.4881

\begin{abstract}
Anaplastic thyroid cancer (ATC) is a rare refractory disease, frequently associated with $B R A F$ mutations and aberrant vascular endothelial growth factor (VEGF) secretion. The antitumor effects of sorafenib were evaluated, and its mechanisms of action were investigated. Four human ATC cell lines were used: OCUT- 4 , which possesses a $B R A F$ mutation; OCUT-6 and ACT-1, which carry NRAS mutations; and OCUT-2, which possesses mutations in BRAF and PI3KCA. The viability of Sorafenib was evaluated by MTT assay. In order to examine the inhibitory effect of Sorafenib on intracellular signal transduction, expression of mitogen-activated protein kinase kinase was examined by western blotting. In addition, cell cycle analysis was performed using flow cytometry. The inhibitory effects of sorafenib on the growth of ATC cells and human umbilical vein endothelial cells (HUVECs) stimulated with conditioned media from ATC cells were examined. Sorafenib inhibited the viability of OCUT-4 more effectively than other ATC cell lines; these effects may have been mediated cytostatically by suppressing mitogen-activated protein kinase kinase phosphorylation. Conversely, similar suppression was not observed in OCUT-6 cells, which possess an NRAS mutation. The four cell lines secreted different quantities of VEGF, and the proliferation of HUVECs was differentially stimulated by their conditioned media. Both anti-VEGF antibody and sorafenib prevented this stimulation of proliferation. In conclusion, sorafenib
\end{abstract}

Correspondence to: Dr Sae Ishihara, Department of Breast and Endocrine Surgery, Osaka City University Graduate School of Medicine, 1-4-3 Asahi-machi, Abeno-ku, Osaka 545-8585, Japan E-mail: saeishihara0910@gmail.com

*Contributed equally

Key words: anaplastic thyroid cancer, sorafenib, BRAF mutation, vascular endothelial growth factor, human umbilical vein endothelial cells more effectively inhibited $R A F$-generated growth signals in ATC cells compared with signals generated by its upstream gene, RAS. ATC cells stimulated the growth of HUVECs via humoral factors, including VEGF; this effect was clearly inhibited by sorafenib. The present findings highlighted the potential of sorafenib for the treatment of ATC and provided insight into its mechanism of action.

\section{Introduction}

Anaplastic thyroid cancer (ATC) is a rare orphan disease, accounting for $1-2 \%$ of all thyroid cancer cases $(1,2)$. Due to its highly malignant potential, patients with ATC often succumb within 6 months of diagnosis despite intensive multimodal therapies, including surgery, chemotherapy and/or radiation therapy $(1,2)$. At present, no effective therapeutic method has been established; thus, development of novel therapeutic strategies for ATC, including molecular-targeted therapy, is highly anticipated. Our previous studies demonstrated the possible effects of molecular therapies targeting peroxisome proliferator activated receptor- $\gamma(3)$, epithelial growth factor receptor (4), B-RAF/mitogen-activated protein kinase kinase (MEK) (5), as well as the effects of an mTOR inhibitor (6). However, the efficacy of these single molecule-targeted agents were limited and depended on the characteristics of specific genetic alteration in the cancer cells. These observations indicated the importance of developing novel therapies targeting multiple molecules or epigenetic mechanisms $(7,8)$.

Sorafenib is a multi-kinase inhibitor targeting RAF, vascular endothelial growth factor (VEGF) receptor (VEGFR) and platelet-derived growth factor receptor (PDGFR) (9), and has been demonstrated to have significant anticancer effects in renal cell carcinoma and hepatocellular carcinoma by prolonging progression-free survival (PFS) and/or overall survival in patients $(10,11)$. In addition, the DECISION trial showed that the mean PFS of patients with radioiodine-refractory differentiated thyroid cancer (RR-DTC) could be extended from 5.8 to 10.8 months following sorafenib therapy compared with that of patients receiving the placebo, leading to approval of sorafenib for clinical treatment of RR-DTC in several countries (12). Phase II trials have also been conducted for the effects of sorafenib in ATC. Although no clinically 
relevant response was demonstrated, disease stabilization was confirmed in certain cases $(13,14)$. Currently, lenvatinib is the only drug approved for clinical use in Japan for patients with unresectable ATC $(15,16)$. Lenvatinib is also a multi-kinase inhibitor targeting similar molecules as sorafenib, including VEGFR and PDGFR, but not the RAF signaling pathway (17). Mutated $B R A F$ is widely known as an important driver gene that promotes the aberrant proliferation of cancer cells (18-20).

A $B R A F$ inhibitor has already been applied as a clinically important therapeutic agent in several types of cancers $(21,22)$. Recent observations indicated that $B R A F$ mutations were more frequent in ATC tumors $(\sim 40 \%)$ (23) than previously considered (24). As previously proposed (5), inhibition of $B R A F$ may be a promising strategy to control cases of ATC involving $B R A F$ mutations. Additionally, ATC cells have been shown to secrete VEGF (25); thus, VEGF-mediated tumor neovascularization is hypothesized to be a strong contributor to the aggressive progression of ATC.

Based on this background, in the present study, the mechanisms underlying the antitumor effects of sorafenib as a multi-molecular targeted therapy agent were investigated using authenticated human ATC cell lines. Additionally, the effects of sorafenib on the impairment of cancer cell-secreted VEGF-mediated tumor neovasculature were evaluated, as well as the inhibition of signal transduction mediated by the RAS/RAF/MEK pathway (Fig. 1).

\section{Materials and methods}

Cell lines and culture conditions. Four authenticated human ATC cell lines were used in the present study, including three cell lines (OCUT-2, OCUT-4 and OCUT-6) established and characterized in our laboratory $(4-6,25)$. These three cell lines were authenticated via STR profiling. The $B R A F$ V600E mutation was found in OCUT-2 and OCUT-4 cells. OCUT-2 cells harbor a mutation of $P I 3 K C A$ in addition to the $B R A F$ mutation, and a NRAS mutation was detected in the OCUT-6 and ACT-1 cell lines (Table I). ACT-1 cells were kindly provided by Dr Seiji Ohata (Tokushima University) (4). Each cell line was cultured in DMEM (Wako Pure Chemical Industries, Ltd.) supplemented with $10 \%$ fetal bovine serum (FBS; Sigma-Aldrich; Merck $\mathrm{KGaA}), 100 \mathrm{IU} / \mathrm{ml}$ penicillin and $100 \mu \mathrm{g} / \mathrm{ml}$ streptomycin at $37^{\circ} \mathrm{C}$ with $5 \% \mathrm{CO}_{2}$ in humidified conditions.

Viability assay. The inhibitory effects of sorafenib on the viability of the ATC cells were measured by an MTT assay (4). Cells $\left(1 \times 10^{3}\right)$ were seeded in each well of a 96-well plastic culture plate and incubated overnight under the aforementioned culture conditions. They were then treated with the indicated dose of sorafenib $(50,100,250,500$ and 1,000 nM; Santa Cruz Biotechnology, Inc.) for 72 h. Subsequently, MTT reagent (Dojindo Molecular Technologies, Inc.) was added to each well at a final concentration of $0.5 \mathrm{mg} / \mathrm{ml}$, and the cells were incubated for a further $2 \mathrm{~h}$ under the same conditions. The culture plate was centrifuged at $200 \mathrm{x}$ g for $5 \mathrm{~min}$ at $25^{\circ} \mathrm{C}$ and the supernatant was removed. Dimethyl sulfoxide was added to dissolve the formazan crystals, and the absorbance at $570 \mathrm{~nm}$ was measured using a microplate reader (Model 550; Bio-Rad Laboratories, Inc.) and calculated using the supplied software (LS-PLATE Manager 2004; Wako Pure Chemical
Industries, Ltd.). The experiments were conducted three times independently, in triplicate each time, and the average values of the three independent experiments were calculated. The efficacy of paclitaxel alone or in combination with sorafenib on cell viability was also measured in the same manner to investigate the synergistic effect of these two drugs in all four cell lines. Cells were exposed to $1-100 \mathrm{nM}$ of paclitaxel for $72 \mathrm{~h}$ with or without $100 \mathrm{nM}$ of sorafenib (equivalent to the estimated IC80 value for each cell line) concomitantly.

Western blotting. BRAF signaling was measured in OCUT-6 cells. The expression and phosphorylation of MEK, a protein downstream of $R A F(5)$, were measured via western blot analysis. OCUT- 4 and OCUT- 6 cells $\left(5 \times 10^{6}\right)$ were incubated for $24 \mathrm{~h}$ with sorafenib $(50 \mathrm{nM})$. After treatment, the cells were lysed in $400 \mu 1$ of $1 \%$ Triton in PBS and gently agitated for $20 \mathrm{~min}$. Protein was then extracted via centrifugation at $8,050 \mathrm{x} \mathrm{g}$ for $5 \mathrm{~min}$ at $4^{\circ} \mathrm{C}$. The concentration of the protein was measured by BCA method (5). Total protein $(60 \mu \mathrm{g})$ was electrophoresed on a $10 \%$ polyacrylamide gel and transferred to a polyvinylidene fluoride membrane (Trans-Blot Turbo Transfer Pack; Bio-Rad Laboratories, Inc.). The membrane was blocked with $5 \%$ skim milk for $2 \mathrm{~h}$ at room temperature and incubated with a 1:1,000 dilution of anti-human MEK1/2 (cat. no. 8727S), phosphorylated (p)-MEK1/2 (S217/221; cat. no. 9154S; both Cell Signaling Technology, Inc.) and $\beta$-actin (cat. no. A5441; Sigma-Aldrich; Merck KGaA) for $12 \mathrm{~h}$ at $4^{\circ} \mathrm{C}$. After washing three times (10 min each) with $0.1 \%$ Tween 20 in PBS at room temperature, the membrane was incubated for $1 \mathrm{~h}$ at room temperature with a 1:5,000 dilution of peroxidase-conjugated secondary antibody (cat. no. NA934; GE Healthcare Life Sciences), and washed three more times with PBS under the same conditions. The peroxidase activity of the secondary antibody was detected with an enhanced ECL reagent (Immuno Star Zeta; Wako Pure Chemical Industries, Ltd.) and chemiluminescence detection system (ImageQuant LAS 4000mini; GE Healthcare Life Sciences). Densitometry was performed using software (Image Quant TL version 7.0; GE Healthcare Life Sciences). Expression of VEGFR2 on the ATC cells was examined with the same protocol. Anti-VEGFR2 antibody (cat. no. 9698; Cell Signaling Technology, Inc.) was used as the primary antibody, and cultured human umbilical vein endothelial cells (HUVECs; Kurabo Industries Ltd.) were used as a positive control for VEGFR expression.

Cell cycle analysis by flow cytometry. Flow cytometry was used to assess the cell cycle distribution of OCUT- 4 cells treated with sorafenib. OCUT- 4 cells $\left(5 \times 10^{6} / \mathrm{ml}\right)$ treated with $200 \mathrm{nM}$ sorafenib for $1 \mathrm{~h}$ were collected after brief trypsinization, washed with PBS, and fixed with $70 \%$ cold ethanol at $4^{\circ} \mathrm{C}$ for $2 \mathrm{~h}$. The samples were then treated with ribonuclease at $37^{\circ} \mathrm{C}$ for $15 \mathrm{~min}$ (cat. no. R4875; Sigma-Aldrich; Merck $\mathrm{KGaA}$ ) and $10 \mathrm{mg} / \mathrm{l}$ propidium iodide at $4^{\circ} \mathrm{C}$ for $30 \mathrm{~min}$ (Sigma-Aldrich; Merck KGaA), and analyzed using a cell sorter (FACScan LSR II; BD Biosciences). Cell cycle distributions were quantified using ModFit LT version 5.0 software (Verity Software House).

Measurement of VEGF in the culture medium. Cells of all four cell lines $\left(1 \times 10^{5}\right)$ were seeded on a $10-\mathrm{mm}$ plastic culture plate 
Table I. Characteristics of the anaplastic thyroid cancer cell lines.

\begin{tabular}{|c|c|c|c|c|c|c|c|c|c|}
\hline \multirow[b]{2}{*}{ Cell line } & \multicolumn{6}{|c|}{ Gene mutation } & \multirow[b]{2}{*}{$\operatorname{VEGF}(\mathrm{pg} / \mathrm{ml})^{\mathrm{a}}$} & \multicolumn{2}{|c|}{$\mathrm{IC}_{50}(\mathrm{nM})$} \\
\hline & $N R A S$ & $B R A F$ & $A K T 1$ & PI3KCA & P53 & hTERT & & Sorafenib & Paclitaxel \\
\hline ACT-1 & Q61K & wt & wt & wt & C242S & C250T Hetero & 409 & $680 \pm 50^{\mathrm{b}}$ & $4.45 \pm 1.26$ \\
\hline OCUT-2 & wt & V600E & wt & H1047R & wt & C250T Homo & 849 & $700 \pm 75^{b}$ & $8.70 \pm 0.05$ \\
\hline OCUT-4 & wt & V600E & wt & wt & wt & C228T Homo & 64.5 & $200 \pm 30$ & $3.35 \pm 0.76$ \\
\hline OCUT-6 & Q61R & wt & wt & wt & $\mathrm{wt}$ & C228T Hetero & 142 & $550 \pm 50^{\mathrm{b}}$ & $3.67 \pm 0.31$ \\
\hline
\end{tabular}

Data are presented as mean \pm SD. ${ }^{a}$ In conditioned medium; ${ }^{\mathrm{b}} \mathrm{P}<0.05 \mathrm{vs}$. OCUT-4. PI3KCA, PI3K catalytic subunit $\alpha$; hTERT, human telomerase reverse transcriptase; VEGF, vascular endothelial growth factor.

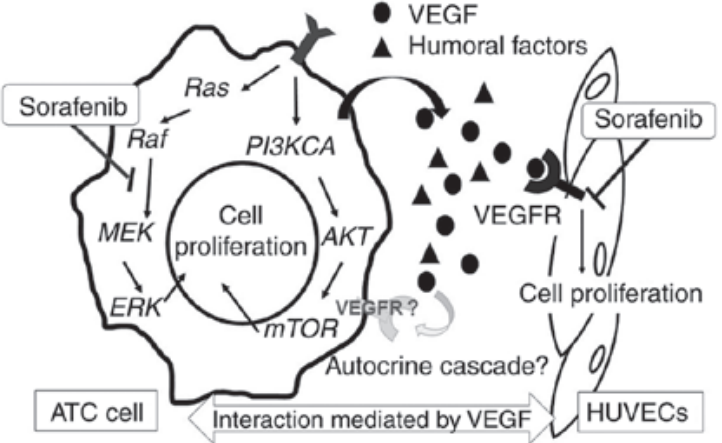

Figure 1. Proposed schematic of sorafenib action. The mechanisms via which sorafenib inhibits the growth of ATC were investigated by analyzing alterations to the RAS/RAS/MEK signal cascade, and the VEGF-mediated interactions between cancer cells and HUVECs. ATC, anaplastic thyroid cancer; HUVEC, human umbilical vein endothelial cell; MEK, mitogen-activated protein kinase kinase; PI3KCA, PI3K catalytic subunit $\alpha$; VEGF, vascular endothelial growth factor; VEGFR, VEGF receptor.

in $5 \mathrm{ml}$ of fresh medium, and cultured for $48 \mathrm{~h}$. The supernatant was sampled and filtered (MILLEX-GV Filter Unit; Merck $\mathrm{KGaA}$ ) to prepare conditioned medium. The concentration of VEGF in the conditioned medium was measured via ELISA (cat. no. DVE00; LSI Medience Corporation) according to the manufacturer's protocols. The concentration of VEGF in the fresh medium was confirmed to be below the detectable level of the assay.

Effects of ATC conditioned medium and sorafenib on HUVECs. To investigate the effects of sorafenib on the impairment of cancer-secreted VEGF-mediated tumor neovasculature, the proliferation of HUVECs was measured following stimulation by conditioned medium from the supernatant of all four ATC cells, in the presence or absence of sorafenib. Cryopreserved HUVECs were purchased and prepared according to the manufacturer's protocols before use for the experiment. HUVECs were thawed and incubated at $37^{\circ} \mathrm{C}$ with $5 \% \mathrm{CO}_{2}$ in low-serum primary culture medium (HuMedia-EB2 plus 2\% fetal bovine serum, $10 \mathrm{ng} / \mathrm{ml}$ human epidermal growth factor, $1.34 \mu \mathrm{g} / \mathrm{ml}$ hydrocortisone, $50 \mu \mathrm{g} / \mathrm{ml}$ gentamicin, $50 \mu \mathrm{g} / \mathrm{ml}$ amphotericin $\mathrm{B}, 5 \mathrm{ng} / \mathrm{ml}$ human fibroblast growth factor-B and $10 \mu \mathrm{g} / \mathrm{ml}$ heparin; all Kurabo Industries, Ltd.) to promote constant growth. Primary culture medium was completely removed prior to each experiment. Prepared HUVECs $\left(3 \times 10^{3}\right)$ were seeded in each well of a 96-well plastic culture plate and left overnight in a total of $100 \mu \mathrm{l}$ culture medium. Subsequently, $100 \mu \mathrm{l}$ of either fresh culture medium or conditioned medium was added to each well along with $1 \mathrm{nM}$ VEGF (positive control; rhVEGF-A165; Wako Pure Chemical Industries, Ltd.), 1 nM VEGF-blocking antibody (block control; bevacizumab; Chugai Pharmaceutical Co., Ltd.) and/or sorafenib (1 or $10 \mathrm{nM}$ ). After culturing for a further $48 \mathrm{~h}$, the supernatant was discarded, and the HUVECs were stained with Mayer's hematoxylin solution (Wako Pure Chemical Industries, Ltd.) for $30 \mathrm{~min}$ at room temperature. Each well was washed with tap water and dried. The number of cells in the middle of the well was counted under three separate high-power fields (magnification, x40) of a light microscope. The average counts of three separate experiments were calculated.

Statistics. Statistical analysis was performed using SPSS version 22 (IBM Corp.). The differences of variables were examined using ANOVA (parametric) or Kruskal-Wallis (non-parametric) tests to analyze differences between multiple groups. Tukey (parametric) or Games-Howell (non-parametric) tests were used as post hoc tests. $\mathrm{P}<0.05$ was considered statistically significant.

\section{Results}

Effects of sorafenib on cell viability. The inhibitory effects of sorafenib on ATC cells were most pronounced in OCUT-4 cells, which possess $B R A F$ mutations only, when treated at moderately high concentrations $(>100 \mathrm{nM})$. Higher concentrations $(>500 \mathrm{nM})$ of sorafenib were required to observe equivalent inhibitory effects on cell viability in the OCUT-2, OCUT-6 and ACT-1 cell lines (Fig. 2). Paclitaxel showed strong inhibitory effects regardless of gene mutation status or sensitivity to sorafenib (Table I; only $\mathrm{IC}_{50}$ values are shown). With combined treatment of sorafenib + paclitaxel, only additive effects were observed; no synergistic effects were reported in any cell line investigated (Fig. 3).

Effects of sorafenib on RAF/MEK signaling. The mechanism via which sorafenib caused cellular damage was investigated by evaluating alterations in downstream signal transduction from the $R A F$ gene and cell cycle analysis. The phosphorylation of 


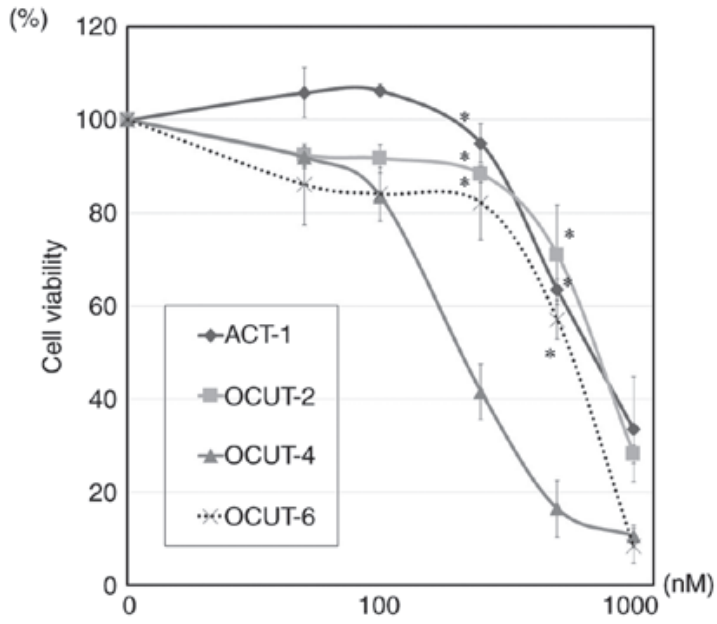

Figure 2. Dose-dependent effects of sorafenib on the viability of anaplastic thyroid cancer cell lines. Cell viability was measured using an MTT assay. The strongest effects were observed in OCUT- 4 cells, which possess a mutation in $B R A F .{ }^{*} \mathrm{P}<0.05$ vs. OCUT- 4 .

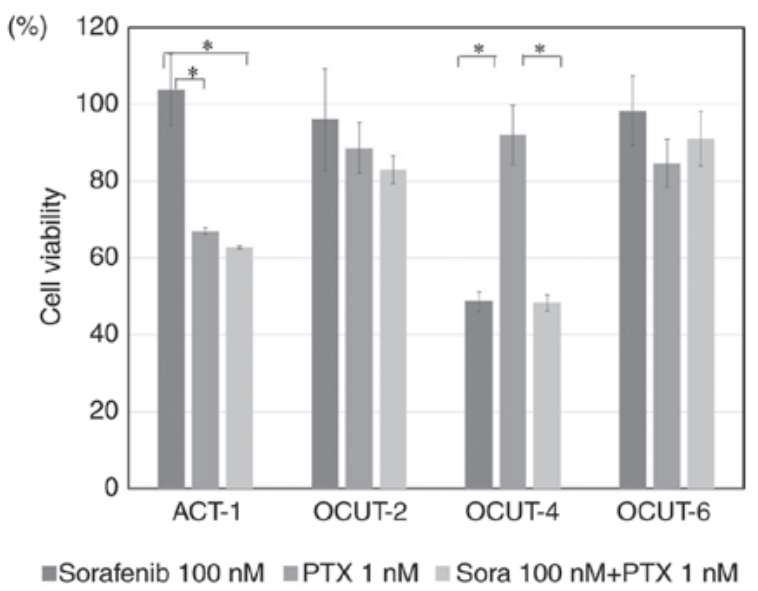

Figure 3. Additive effect of sorafenib to paclitaxel-induced cellular damage of anaplastic thyroid cancer cell lines. Sorafenib $(100 \mathrm{nM})$ and/or paclitaxel $(1 \mathrm{nM})$ was added to cells; cell viability was measured using an MTT assay. ${ }^{*} \mathrm{P}<0.05$. ptx, paclitaxel.

MEK, a direct downstream kinase of RAF, was clearly downregulated by sorafenib treatment in OCUT- 4 cells. In contrast, p-MEK was upregulated by sorafenib in OCUT-6 cells, a sorafenib-insensitive cell line with a RAS mutation (Fig. 4). Moreover, there was a clear increase of the G0/G1-phase cell fraction (50.5 to 59.9\%) and a simultaneous decrease in the S-phase fraction (41.5 to 31.7\%) after treatment with sorafenib in OCUT-4 cells. No sub-G0 cell fraction, indicative of apoptotic cell death, was identified after sorafenib treatment (Fig. 5).

VEGF secretion by ATC cells. The secretion of VEGF was confirmed in every ATC cell line examined. The concentration of VEGF varied among cell lines without a clear association with the efficacy of sorafenib (Table I). OCUT-4 cells secreted the lowest concentration of VEGF in the culture medium but showed the highest sensitivity to sorafenib. Moreover, the expression of VEGFR could not be confirmed in any of the

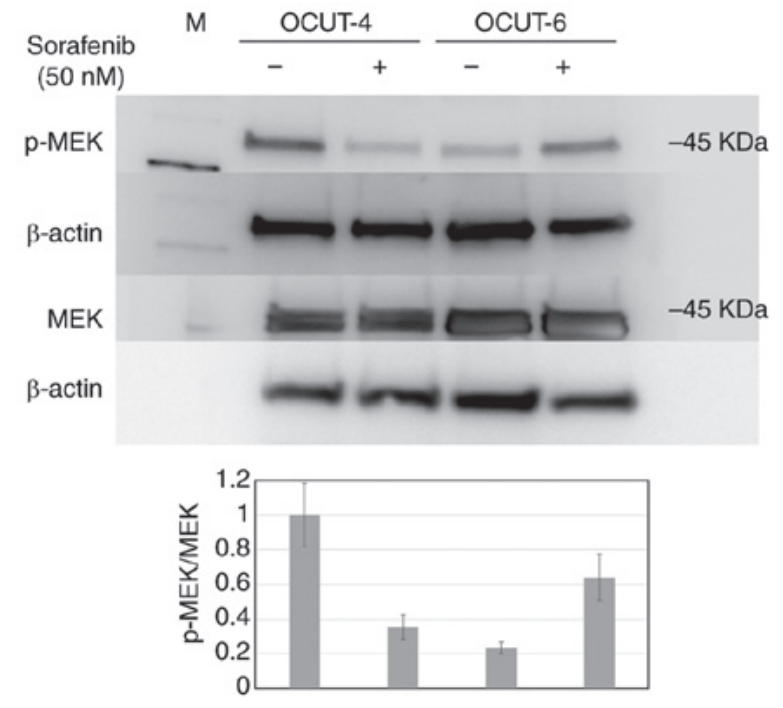

Figure 4. Effect of sorafenib on the phosphorylation of MEK in anaplastic thyroid cancer cell lines. Western blotting was performed to evaluate the phosphorylation and expression of MEK, p-MEK/MEK was downregulated in OCUT-4 cells following sorafenib treatment, but upregulated in OCUT-6 cells $(n=3)$. M, molecular marker; MEK, mitogen-activated protein kinase kinase; p, phosphorylated.

ATC cell lines investigated (data not shown). Therefore, the existence of an autocrine cell growth stimulation cascade mediated by VEGF and its receptor was not identified in the experimental ATC cells.

Effect of VEGF and ATC cells on HUVEC proliferation. VEGF clearly stimulated the proliferation of HUVECs, and this effect was completely blocked by sorafenib to a similar extent as observed with anti-VEGF antibody (Fig. 6). Moreover, the conditioned medium of all ATC cell lines could also significantly stimulate the proliferation of HUVECs (Fig. 7; data of OCUT-2 and ACT-1 not shown). Although this stimulation was not completely suppressed by VEGF blockade, sorafenib significantly inhibited the conditioned medium-induced proliferation of HUVECs. The inhibitory effect of sorafenib on VEGF/ATC cell-stimulated HUVEC proliferation was evident within a much lower concentration range (1-10 $\mathrm{nM})$ than that required to reduce cancer cell viability (>100 nM). Similar results were observed for all ATC cell lines investigated, despite variation between cell lines in the quantity of VEGF secreted in the conditioned medium.

\section{Discussion}

Sorafenib, a multi-kinase inhibitor, impairs the signal transduction generated by $R A F$-family genes. Sorafenib also inhibits the tyrosine kinase activities of VEGFR-1, $-2,-3$, PDGFR- $\beta$, RET, c-Kit and Fms-like tyrosine kinase 3, and blocks initiating downstream signals (14). Theoretically, and based on experiments using various cancer cell lines, these mechanisms may underlie aberrant cancer cell proliferation (26). ATC tumors commonly harbor driver gene alterations in the RAS/RAF/MEK signaling cascade that contribute to the aggressive proliferation of cancer cells (23), and ATC cells often secrete several growth factors or cytokines, such as 

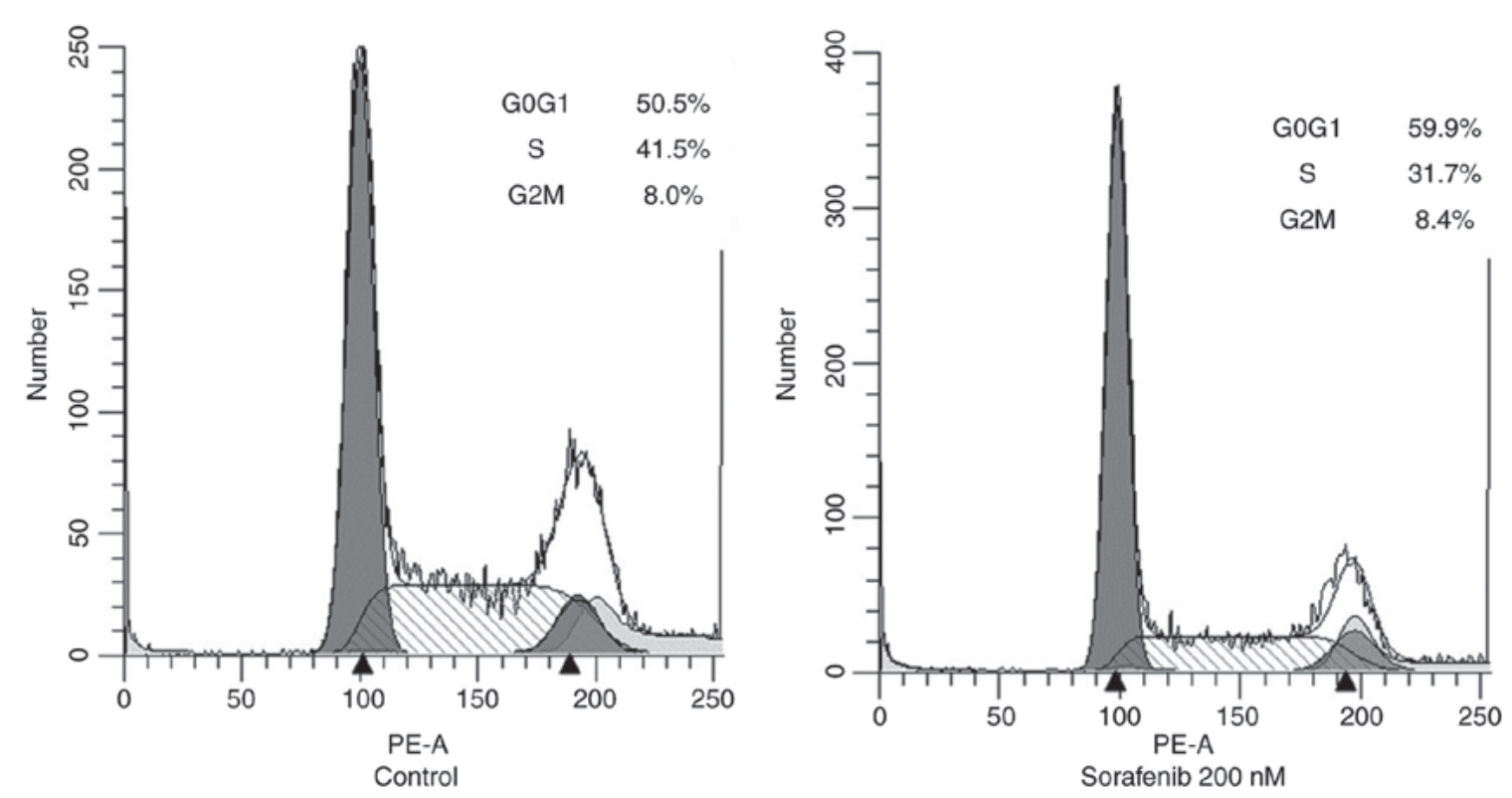

Figure 5. Cell cycle distribution of OCUT-4 anaplastic thyroid cancer cells after exposure to sorafenib. OCUT-4 cells were treated with $200 \mathrm{nM}$ sorafenib based on the $\mathrm{IC}_{50}$ of the compound in this cell. Sorafenib treatment resulted in an increased G0/G1 fraction and decreased S phase cell fraction compared with the control, indicating G1 arrest. No measurable sub-G0 population was detected after sorafenib exposure.

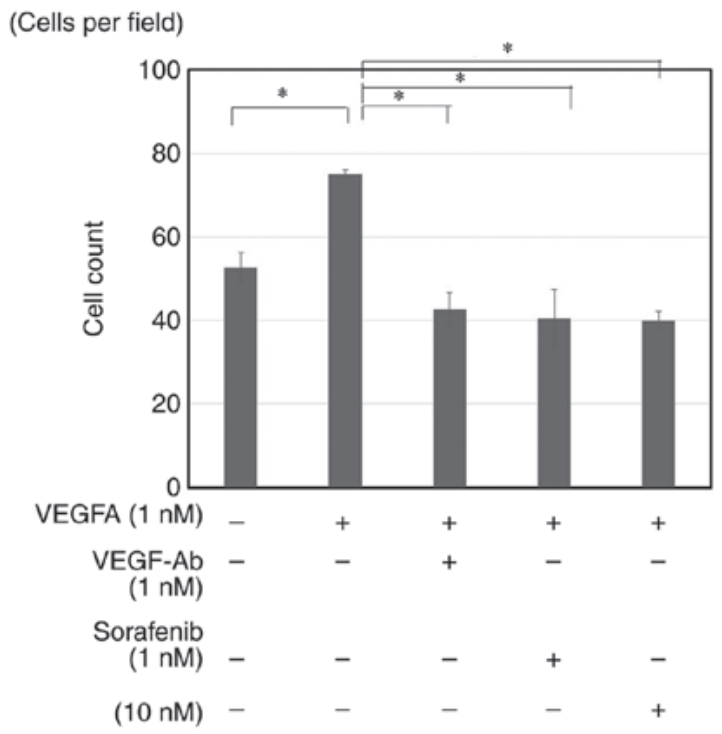

Figure 6. Number of HUVECs after VEGF stimulation with or without sorafenib. HUVECs were treated with VEGFA, which induced an increase in cell number that was blocked by sorafenib (1 or $10 \mathrm{nM})$ or VEGF-Ab $(1 \mathrm{nM})$. ${ }^{*} \mathrm{P}<0.05$. HUVEC, human umbilical vein endothelial cell; VEGF, vascular endothelial growth factor; VEGF-Ab, antibody specific for VEGF.

VEGF, to establish suitable microenvironments for cancer progression (27). Therefore, sorafenib may be a viable agent for the treatment of ATC. Nevertheless, its detailed mechanism of action in ATC warrants further investigation.

It was demonstrated that sorafenib was more effective at regulating cellular proliferation in ATC cells harboring $B R A F$ mutations than cell lines possessing a $R A S$ mutation, or simultaneous $B R A F$ and PI3KCA mutations. The relationship between genetic abnormalities and effects on cellular viability has been demonstrated using breast, colon or pancreatic cancer cell lines (26), as well as ATC cell lines (28). Sorafenib has been shown to inhibit cell lines possessing wild-type $B R A F$, or mutated $B R A F$ or $C R A F$. However, in all these previous reports, a high dose of sorafenib was required to suppress the abundant growth signals generated by mutated $R A S$, a gene upstream of $R A F$ (26). Consistent with these reports, it was observed that $>500 \mathrm{nM}$ of sorafenib was required to impair the viability of ATC cells with $R A S$ mutations. Kim et al (28) examined both in vitro and in vivo effects of sorafenib in their study using 5 ATC cell lines of known $B R A F$ mutation status. Although they reported the apoptotic cell death of ATC cells irrespective of $B R A F$ mutation status after treatment with sorafenib, they used very high concentrations $(>5,000 \mathrm{nM})$. Here, the induction of cell cycle arrest in sorafenib-sensitive, BRAF-mutated OCUT-4 cells by low concentrations of sorafenib (50-200 nM) was demonstrated, potentially due to inhibition of MEK phosphorylation. Thus, the main mechanism of cancer cell damage by sorafenib appears to be due to cell cycle arrest via targeting RAF as opposed to apoptosis induction. The present findings suggested that ATC cells or tumors harboring BRAF mutations may be a more viable target of sorafenib treatment.

The secretion of VEGF from ATC cells leads to vigorous tumor neovascularization to enable aggressive cancer growth (25). VEGF also affects existing vessels to increase the permeability of the vascular wall, facilitating the migration of cancer cells into vessels (29), a fundamental step for metastasis. These effects are mediated by the phosphorylation of VEGFR on vascular endothelial cells. Indeed, VEGFR expression on cancer cells has been reported $(28,30)$, which enables accelerating proliferation via autocrine growth factor signaling cascades. However, VEGFR expression was not detected in the ATC cell lines used in the present study, suggesting that the VEGF-VEGFR autocrine cascade may be limited in ATC.

Kim et al (28) investigated intratumoral microvessels in an orthotopic ATC xenograft model to demonstrate the antiangiogenic effect of sorafenib. They concluded that sorafenib has 

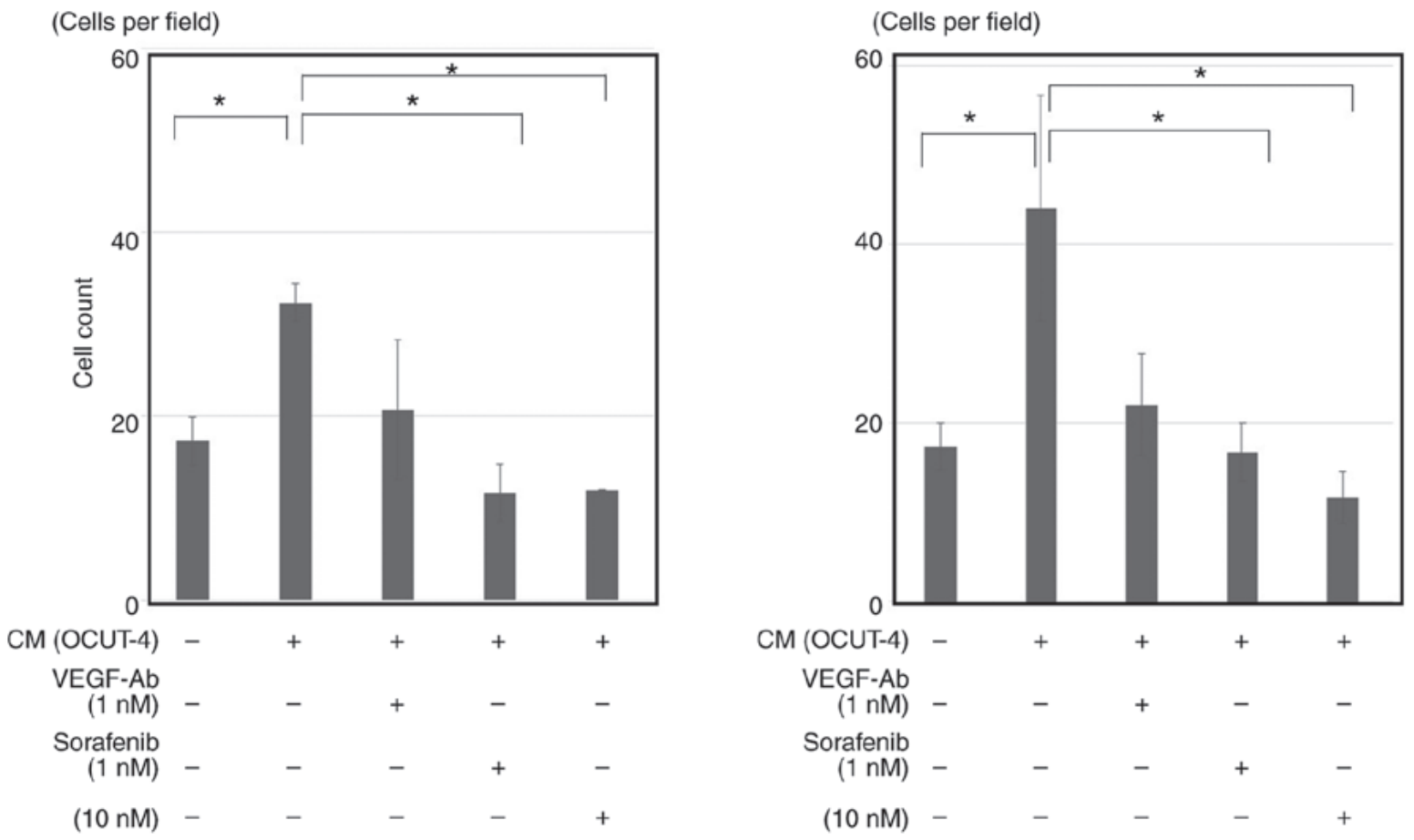

Figure 7. CM from ATC cell lines stimulates HUVEC growth. HUVECs were treated with CM obtained from the supernatant of cultured ATC cells, which promoted cell growth (data from HUVECs treated with CM of OCUT-2 or ACT-1 cells not shown). This stimulation was inhibited by sorafenib regardless of mutation status. "P $<0.05$. ATC, anaplastic thyroid cancer; CM, conditioned medium; HUVEC, human umbilical vein endothelial cell; VEGF, vascular endothelial growth factor; VEGF-Ab, antibody specific for VEGF.

more effective anticancer effects by impairing modifications to the tumor vasculature rather than direct effects on cancer cells, based on pathological comparisons of the damage to microvessels and cancer cells. Previous reports suggested that impairment of the VEGF-mediated proliferation of the tumor neovasculature is the primary anticancer mechanism of sorafenib $(26,28)$. However, the effects of sorafenib on the interactions between cancer cells and vascular endothelial cells are yet to be fully determined.

In the present study, the stimulation of HUVEC proliferation by humoral factors secreted from ATC cells was demonstrated, which was partially blocked by anti-VEGF blockade, but more markedly inhibited by sorafenib. Although additional studies to determine the involvement of other humoral factors such as PDGF are required, these results indicated that the antitumor effects of sorafenib are primarily due to the impairment of tumor vascularization stimulated by humoral factors, including VEGF, from ATC cells.

Clinical trials have not yet demonstrated a clear therapeutic effect of sorafenib alone on ATC $(13,14)$. Based on the present findings: i) Sorafenib requires high dose to show significant direct inhibition of cell growth; ii) the effects of sorafenib are detected in the form of cell cycle arrest but not apoptosis; and iii) activation of PI3K/AKT/mTOR signaling pathway in addition to RAS/RAF/MEK, often found in ATC, can involve in sorafenib resistance. These properties may result in inadequate clinical efficacy in treating ATC using sorafenib. Several synergistic combinations have been reported to enhance the therapeutic effect of sorafenib $(31,32)$. The potential synergistic effect of paclitaxel, an effective drug recommended to manage ATC clinically $(33,34)$, combined with sorafenib were evaluated; however, no synergistic effect was observed. A previous study reported enhancement of the antitumor effects of paclitaxel against ATC cells by lenvatinib both in vitro and in vivo (35). They suggested not only the cell viability, but also the apoptosis and G2-M cell cycle arrest induced by paclitaxel were significantly enhanced with concomitant lenvatinib treatment. However, it is difficult to directly compare these results with the present findings, as high doses of lenvatinib (40-fold higher than sorafenib used in this study) and paclitaxel (250-fold higher concentrations as used in this study) were required to demonstrate synergistic effects in the previous study. Future directions may include evaluations of molecular targeted drugs $(5,36)$ or immune-checkpoint inhibitors (37) as possible partners to strengthen the efficacy of sorafenib for its clinical application in treating ATC.

The present study possesses several limitations. First, the experiments focused on the investigation of the cancer cell-damaging mechanisms of sorafenib in a sorafenib-sensitive ATC cell line, OCUT-4. Conversely, the mechanisms in sorafenib-resistant cell lines were not investigated in detail; further studies comparing the present results to those obtained in other cell lines are required to confirm the proposed mechanisms of action of sorafenib. Second, the effect of sorafenib on VEGF secretion from ATC cells was not studied. This should be studied in future experiments to clarify the specific action of sorafenib on VEGFR. Third, the concentration of only VEGF in the conditioned medium was measured. The involvement of other humoral factors should be studied further, as well as their secretion levels compared with VEGF, in order to reveal the most important factor or factors responsible for cancer progression and sorafenib sensitivity.

In conclusion, the present study suggested that sorafenib more effectively inhibited $R A F$-generated growth signals in 
ATC cells compared to those generated by its upstream gene, $R A S$. ATC cells stimulated the growth of endothelial cells via the secretion of humoral factors, including VEGF; this effect was inhibited by sorafenib. Although a suitable partner for clinically effective combination therapy should be identified to improve clinical response, the present observations indicated that sorafenib has a certain degree of therapeutic potential for the management of ATC.

\section{Acknowledgements}

The authors thank Yayoi Matsukiyo (Osaka City University) for preparing the experiment.

\section{Funding}

Part of this study was supported by a research grant on the 'Investigation of the efficacy of multi-kinase inhibitor in anaplastic thyroid cancer' awarded by Bayer Medical Affairs (Osaka, Japan).

\section{Availability of data and materials}

The datasets used and/or analysed during the current study are available from the corresponding author on reasonable request.

\section{Authors' contributions}

NO was involved in the conception of the study, and SI, NO, YA, YT, TM, SK, TT and MO were involved in the design of the study. SI, NO, SN, SK and YA performed experiments and the statistical analysis. SI and NO wrote the initial draft of the manuscript. NO, SN, YT, TM, SK, TT and MO were involved in reviewing and editing the manuscript. NO supervised the study and provided funding.

\section{Ethics approval and consent to participate}

Not applicable.

\section{Patient consent for publication}

Not applicable.

\section{Competing interests}

NO received honoraria from Eisai, Bayer, and Sanofi, and research funding from Eisai and Bayer. SN received research funding from Eisai. SK received honoraria and research funding from Eisai. SI, YA, YT, TM, TT and MO have nothing to declare. The funders had no role in the design of the study; in the collection, analyses, or interpretation of data; in the writing of the manuscript, or in the decision to publish the results.

\section{References}

1. Sugitani I, Miyauchi A, Sugino K, Okamoto T, Yoshida A and Suzuki S: Prognostic factors and treatment outcomes for anaplastic thyroid carcinoma: ATC Research Consortium of Japan cohort study of 677 patients. World J Surg 36: 1247-1254, 2012.
2. Haymart MR, Banerjee M, Yin H, Worden F and Griggs JJ: Marginal treatment benefit in anaplastic thyroid cancer. Cancer 119: 3133-3139, 2013.

3. Chung SH, Onoda N, Ishikawa T, Ogisawa K, Takenaka C, Yano Y, Hato F and Hirakawa K: Peroxisome proliferator-activated receptor gamma activation induces cell cycle arrest via the p53-independent pathway in human anaplastic thyroid cancer cells. Jpn J Cancer Res 93: 1358-1365, 2002.

4. Nobuhara Y, Onoda N, Yamashita Y, Yamasaki M, Ogisawa K, Takashima T, Ishikawa T and Hirakawa K: Efficacy of epidermal growth factor receptor-targeted molecular therapy in anaplastic thyroid cancer cell lines. Br J Cancer 92: 1110-1116, 2005.

5. Kurata K, Onoda N, Noda S, Kashiwagi S, Asano Y, Hirakawa K and Ohira M: Growth arrest by activated BRAF and MEK inhibition in human anaplastic thyroid cancer cells. Int J Oncol 49: 2303-2308, 2016.

6. Onoda N, Nakamura M, Aomatsu N, Noda S, Kashiwagi S, Kurata K, Uchino S and Hirakawa K: Significant cytostatic effect of everolimus on a gefitinib-resistant anaplastic thyroid cancer cell line harboring PI3KCA gene mutation. Mol Clin Oncol 3: 522-526, 2015.

7. Kasaian K, Wiseman SM, Walker BA, Schein JE, Zhao Y, Hirst M, Moore RA, Mungall AJ, Marra MA and Jones SJ: The genomic and transcriptomic landscape of anaplastic thyroid cancer: Implications for therapy. BMC Cancer 15: 9842015.

8. Molinaro E, Romei C, Biagini A, Sabini E, Agate L, Mazzeo S, Materazzi G, Sellari-Franceschini S, Ribechini A, Torregrossa L, et al: Anaplastic thyroid carcinoma: From clinicopathology to genetics and advanced therapies. Nat Rev Endocrinol 13: 644-660, 2017.

9. Yi H, Ye X, Long B, Ye T, Zhang L, Yan F, Yang Y and Li L: Inhibition of the AKT/mTOR pathway augments the anticancer effects of sorafenib in thyroid cancer. Cancer Biother Radiopharm 32: 176-183, 2017.

10. Llovet JM, Ricci S, Mazzaferro V, Hilgard P, Gane E, Blanc JF, de Oliveira AC, Santoro A, Raoul JL, Forner A, et al: Sorafenib in advanced hepatocellular carcinoma. N Engl J Med 359: 378-390, 2008

11. Escudier B, Eisen T, Stadler WM, Szczylik C, Oudard S, Siebels M, Negrier S, Chevreau C, Solska E, Desai AA, et al: Sorafenib in advanced clear-cell renal-cell carcinoma. N Engl J Med 356: 125-134, 2007.

12. Brose MS, Nutting CM, Jarzab B, Elisei R, Siena S, Bastholt L, de la Fouchardiere C, Pacini F, Paschke R, Shong YK, et al: Sorafenib in radioactive iodine-refractory, locally advanced or metastatic differentiated thyroid cancer: A randomised, double-blind, phase 3 trial. Lancet 384: 319-328, 2014.

13. Savvides P, Nagaiah G, Lavertu P, Fu P, Wright JJ, Chapman R, Wasman J, Dowlati A and Remick SC: Phase II trial of sorafenib in patients with advanced anaplastic carcinoma of the thyroid. Thyroid 23: 600-604, 2013.

14. Ito Y, Onoda N, Ito KI, Sugitani I, Takahashi S, Yamaguchi I, Kabu K and Tsukada K: Sorafenib in japanese patients with locally advanced or metastatic medullary thyroid carcinoma and anaplastic thyroid carcinoma. Thyroid 27: 1142-1148, 2017.

15. Tahara M, Kiyota N, Yamazaki T, Chayahara N, Nakano K, Inagaki L, Toda $\mathrm{K}$, Enokida T, Minami $\mathrm{H}$, Imamura $\mathrm{Y}$, et al: Lenvatinib for anaplastic thyroid cancer. Front Oncol 7: 25, 2017.

16. Sugitani I, Onoda N, Ito KI and Suzuki S: Management of anaplastic thyroid carcinoma: The fruits from the ATC research consortium of Japan. J Nippon Med Sch 85: 18-27, 2018.

17. Brose MS, Worden FP, Newbold KL, Guo M and Hurria A: Effect of age on the efficacy and safety of lenvatinib in radioiodine-refractory differentiated thyroid cancer in the phase III SELECT trial. J Clin Oncol 35: 2692-2699, 2017.

18. Zaman A, Wu W and Bivona TG: Targeting oncogenic BRAF: Past, present, and future. Cancers (Basel) 11: E1197, 2019.

19. Sanz-Garcia E, Argiles G, Elez E and Tabernero J: BRAF mutant colorectal cancer: Prognosis, treatment, and new perspectives. Ann Oncol 28: 2648-2657, 2017.

20. Ascierto PA, Kirkwood JM, Grob JJ, Simeone E, Grimaldi AM, Maio M, Palmieri G, Testori A, Marincola FM and Mozzillo N: The role of BRAF V600 mutation in melanoma. J Transl Med 10: $85,2012$.

21. Schreuer M, Jansen Y, Planken S, Chevolet I, Seremet T, Kruse V and Neyns B: Combination of dabrafenib plus trametinib for BRAF and MEK inhibitor pretreated patients with advanced BRAF ${ }^{\mathrm{V} 600}$-mutant melanoma: An open-label, single arm, dual-centre, phase 2 clinical trial. Lancet Oncol 18: 464-472, 2017. 
22. Planchard D, Besse B, Groen HJM, Souquet PJ, Quoix E, Baik CS, Barlesi F, Kim TM, Mazieres J, Novello S, et al: Dabrafenib plus trametinib in patients with previously treated BRAF(V600E)-mutant metastatic non-small cell lung cancer: An open-label, multicentre phase 2 trial. Lancet Oncol 17: 984-993, 2016.

23. Pozdeyev N, Gay LM, Sokol ES, Hartmaier R, Deaver KE, Davis S, French JD, Borre PV, LaBarbera DV, Tan AC, et al: Genetic analysis of 779 advanced differentiated and anaplastic thyroid cancers. Clin Cancer Res 24: 3059-3068, 2018.

24. Wang HM, Huang YW, Huang JS, Wang CH, Kok VC, Hung CM, Chen HM and Tzen CY: Analastic carcinoma of the thyroid arising more often from follicular carcinoma than papillary carcinoma. Ann Surg Oncol 14: 3011-3018, 2007.

25. Onoda N, Nakamura M, Aomatsu N, Noda S, Kashiwagi S and Hirakawa K: Establishment, characterization and comparison of seven authentic anaplastic thyroid cancer cell lines retaining clinical features of the original tumors. World J Surg 38: 688-695, 2014.

26. Wilhelm SM, Carter C, Tang L, Wilkie D, McNabola A, Rong H, Chen C, Zhang X, Vincent P, McHugh M, et al: BAY 43-9006 exhibits broad spectrum oral antitumor activity and targets the $\mathrm{RAF} / \mathrm{MEK} / \mathrm{ERK}$ pathway and receptor tyrosine kinases involved in tumor progression and angiogenesis. Cancer Res 64: 7099-7109, 2004.

27. Costache MI, Ioana M, Iordache S, Ene D, Costache CA and Săftoiu A: VEGF expression in pancreatic cancer and other malignancies: A review of the literature. Rom J Intern Med 53. 199-208, 2015

28. Kim S, Yazici YD, Calzada G, Wang ZY, Younes MN, Jasser SA, El-Naggar AK and Myers JN: Sorafenib inhibits the angiogenesis and growth of orthotopic anaplastic thyroid carcinoma xenografts in nude mice. Mol Cancer Ther 6: 1785-1792, 2007.

29. Ferrara N, Gerber HP and LeCouter J: The biology of VEGF and its receptors. Nat Med 9: 669-676, 2003.

30. D'Haene N, Koopmansch C, Van Eycke YR, Hulet F, Allard J, Bouri S, Rorive S, Remmelink M, Decaestecker C, Maris C and Salmon I: The prognostic value of the combination of low VEGFR-1 and High VEGFR-2 expression in endothelial cells of colorectal cancer. Int J Mol Sci 19: pii: E3536, 2018.
31. Chen G, Nicula D, Renko K and Derwahl M: Synergistic anti-proliferative effect of metformin and sorafenib on growth of anaplastic thyroid cancer cells and their stem cells. Oncol Rep 33: 1994-2000, 2015

32. Wang H, Zhang C, Ning Z, Xu L, Zhu X and Meng Z: Bufalin enhances anti-angiogenic effect of sorafenib via AKT/VEGF signaling. Int J Oncol 48: 1229-1241, 2016.

33. Higashiyama T, Ito Y, Hirokawa M, Fukushima M, Uruno T, Miya A, Matsuzuka F and Miyauchi A: Induction chemotherapy with weekly paclitaxel administration for anaplastic thyroid carcinoma. Thyroid 20: 7-14, 2010

34. Onoda N, Sugino K, Higashiyama T, Kammori M, Toda K, Ito K, Yoshida A, Suganuma N, Nakashima N, Suzuki S, et al: The safety and efficacy of weekly paclitaxel administration for anaplastic thyroid cancer patients: A nationwide prospective study. Thyroid 26: 1293-1299, 2016.

35. Jing C, Gao Z, Wang R, Yang Z, Shi B and Hou P: Lenvatinib enhances the antitumor effects of paclitaxel in anaplastic thyroid cancer. Am J Cancer Res 7: 903-912, 2017.

36. Subbiah V, Kreitman RJ, Wainberg ZA, Cho JY, Schellens JHM, Soria JC, Wen PY, Zielinski C, Cabanillas ME, Urbanowitz G, et al: Dabrafenib and trametinib treatment in patients with locally advanced or metastatic BRAF V600-mutant anaplastic thyroid cancer. J Clin Oncol 36: 7-13, 2018.

37. Gunda V, Gigliotti B, Ndishabandi D, Ashry T, McCarthy M, Zhou Z, Amin S, Freeman GJ, Alessandrini A and Parangi S: Combinations of BRAF inhibitor and anti-PD-1/PD-L1 antibody improve survival and tumour immunity in an immunocompetent model of orthotopic murine anaplastic thyroid cancer. Br J Cancer 119: 1223-1232, 2018

This work is licensed under a Creative Commons Attribution-NonCommercial-NoDerivatives 4.0 International (CC BY-NC-ND 4.0) License. 